\title{
HARPADAS LENGUAS O LA PRIMERA APARICIÓN DE LA VIRGEN DE GUADALUPE. \\ SOBRE EL GONGORISMO DE FRANCISCO DE CASTRO
}

Las versiones de las mariofanías guadalupanas impresas durante el siglo XVII presentan mínimas, pero significativas diferencias. Para Luis Becerra Tanco, por ejemplo, el Tepeyac es "un cerro pequeño... significa extremidad o remate agudo de los cerros, porque sobresale a los demás montes que rodean el valle y laguna en que yace la ciudad de México"1. Para Miguel Sánchez, en cambio, es "un monte o cerro tosco, pedregoso e inculto, con alguna eminencia bastante para poder atalayar a todos sus contornos" ${ }^{2}$. En la Primavera indiana, Carlos de Sigüenza y Góngora amplifica las fugaces observaciones de Sánchez y desarrolla un tema poético productivo: la descripción más o menos pormenorizada del cerro antes de las apariciones. Productivo en un doble sentido. Por un lado, el Tepeyac se convierte en el espacio privilegiado para desplegar el mundo de reminiscencias mitológicas que exige la poesía gongorina. Así, como los gigantes, el Tepeyac perturba momentáneamente la tranquilidad del cielo (oct. 9) o bien su esterilidad se remonta al ciclo de Faetón, quien lo habría quemado cuando guiaba el carro de su padre (oct. 4). La amplificatio mítica bosqueja un sitio lúgubre, inhóspito, helado, inaccesible, donde casi no llega la luz del sol. Por otro lado, a nivel estructural, Sigüenza y Góngora opone el cerro sombrío al resplandeciente que revive cual fénix después de la primera aparición:

1 Luis Becerra Tanco, Felicidad de México..., viuda de Bernardo Calderón, México, 1675, f. 1ro; para citar indicaré el número de folio.

2 Miguel SÁnchez, Imagen de la Virgen María Madre de Dios de Guadalupe..., viuda de Bernardo Calderón, México, 1648, f. 19r ${ }^{\circ}$. En adelante, para citar indicaré el número de folio. 
Pero a la vista de ese puro rayo, que el sol empíreo de convexa cumbre desprendió sin recelo de desmayo, se vegetan las flores con su lumbre: rayo has sido del sol, pues vive el mayo, bella María, y con fragante encumbre, si en el inculto monte fénix yace, a vista de tu luz fénix renace ${ }^{3}$.

Al profundizar la dualidad invierno/primavera que subyace en el relato guadalupano, la Primavera indiana establece un elemental sistema de concordancias simbólicas, donde cada elemento de la serie A encuentra su opuesto en la serie B: Tepeyac $\rightarrow$ invierno $\rightarrow$ esterilidad $\rightarrow$ gentilidad $\rightarrow$ noche $\rightarrow$ pecado $/ /$ Tepeyac $\rightarrow$ primavera $\rightarrow$ flores $\rightarrow$ cristianismo $\rightarrow$ día $\rightarrow$ redención ${ }^{4}$. Si bien el claroscuro se encuentra en todo el arte barroco, en el presente caso debe muchísimo al Polifemo gongorino, ordenado, huelga repetirlo, en torno al infernal cíclope y a la celeste Galatea.

En el canto tercero de La octava maravilla y sin segundo milagro (c. 1680), el poeta novohispano Francisco de Castro también describe "la natural tragedia" del Tepeyac: "así por parte de la tierra que le cupo, como del aire que le circunda" (III, sinopsis), estableciendo de este modo un nexo indudable con el poema de Sigüenza y Góngora ${ }^{5}$. El más inmediato se verifica en el empleo

3 Carlos de Sigüenza y Góngora, Primavera indiana. Poema sacro-histórico, idea de María santísima de Guadalupe, copiada de flores, viuda de Bernardo Calderón, México, 1668, octava 17.

${ }^{4}$ Los binomios estaban en potencia en la Imagen de Sánchez. He estudiado con cierta amplitud este aspecto de la Primavera indiana en La función del gongorismo en la "Primavera indiana" de Carlos de Sigüenza y Góngora, tesis, Centro Universitario de Ciencias Sociales y Humanidades, Universidad de Guadalajara, 2009.

${ }^{5}$ Francisco de Castro nació en 1618 o 1619 en Madrid y falleció en México el 6 de septiembre de 1687. Se ignora la fecha en que pudo pasar a América; en todo caso, lo hizo antes de 1641-1642, cuando ingresó a la Provincia de la Compañía de Jesús de Nueva España. El catálogo trienal de 1648 informa que es bachiller en teología, sacerdote de votos simples y que su salud o fortaleza física es mediocre (i.e. mediana). Todavía no ha concluido su formación y cursa el cuarto y último año de teología; tampoco desempeña alguna actividad relacionada con los ministerios de la Compañía. En 1650, concluye su formación y enseña letras humanas. En 1653, apareció enlistado entre los miembros del Collegio missio Cinaloensi. En 1659, salió de las misiones y se encontraba en el Collegium Gualaxarense. Hacia 1659, el padre Castro 
de la misma técnica descriptiva, para generar fuertes contrastes, y en la reelaboración de ciertas imágenes de la Primavera indiana, como la relación del cerro con la fábula de los gigantes (III, 1-2) o su posible origen mítico-geológico (III, 7). En esta amplificación de la amplificación, Castro descubre otras tantas correspondencias eruditas entre el cerro y el mundo clásico ${ }^{6}$ y aprovecha, además, un motivo muy poco atendido por la poesía guadalupana: el dulce canto que oye Juan Diego a su paso por el Tepeyac el día de la primera aparición. Había escrito Sánchez:

empezó a sufrir una enfermedad mental que lo acompañaría el resto de su vida. En 1662, está de regreso en el Colegio Máximo de México y en el Catalogus secretum se vuelve a señalar que tiene el 'juicio afectado'. Nunca hizo el cuarto voto solemne y murió siendo sacerdote de votos simples o profeso de tres votos (castidad, pobreza, obediencia). Los pocos datos biográficos del padre Francisco de Castro se encuentran en el Archivum Romanum Societatis Iesu (Roma), concretamente en los catálogos trienales que los jesuitas de la Provincia de Nueva España remitían a Roma. Referencias bibliográficas

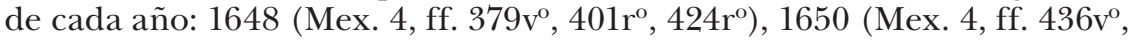
$456 \mathrm{v}^{\circ}$ ), 1653 (Mex. 4, ff. 490v $\mathrm{v}^{\mathrm{o}}, 512 \mathrm{v}^{\mathrm{o}}$ ), 1659 (Mex. 5, ff. $15 \mathrm{r}^{\mathrm{o}}, 35 \mathrm{r}^{\mathrm{o}}$ ), 1662 (Mex. 5, ff. 49ro, $67 \mathrm{r}^{\circ}$ ), 1666 o 1667 (Mex. 5, ff. 111vo $131 \mathrm{v}^{\mathrm{o}}$ ), 1668 (Mex. 5, ff. $153 \mathrm{r}^{\circ}, 169 \mathrm{v}^{\mathrm{o}}$ ), 1671 (Mex. 5, ff. $196 \mathrm{r}^{\circ}, 213 \mathrm{r}^{\circ}$ ), 1674 (Mex. 5, ff. 238r $^{\circ}$, 256r ${ }^{\circ}$ ), 1681 (Mex. 5, ff. 281r ${ }^{\circ}, 302 r^{\circ}$ ), 1684 (Mex. 5, ff. 326v', $349 r^{\circ}$ ), 1687 (Mex. 5, ff. $377 \mathrm{r}^{\circ}, 399 \mathrm{v}^{\circ}$ ). Para una aproximación biográfica, véase T. PABLo STEIN, Épica y gongorismo en la poesía guadalupana: "La octava maravilla y sin segundo milagro" (c. 1680) de Francisco de Castro, tesis, UNAM, 2013, pp. 12-23 y Apéndice II. El poema que nos ocupa fue publicado de forma póstuma en 1729 junto con otro de Juan Carnero en el siguiente volumen: La octava maravilla y sin segundo milagro de México, perpetuado en las rosas de Guadalupe y escrito heroicamente en octavas por el P. Francisco de Castro. Adjunta a las espinas de la Pasión del Hombre dios. Discurridas en el mismo metro/ por el P. Juan Carnero, profesos ambos de la Compañía de Jesús. Conságralas al Niño Dios, por mano de su floridísima Madre María santísima de Guadalupe, el H. Pelayo Vidal, de la misma Compañia. Con licencia, en México, en la Imprenta Real del Superior Gobierno de los herederos de la viuda de Miguel de Rivera Calderón. En el Empedradillo. Año de 1729. En las citas actualizo puntuación y ortografía. (Hay dos ediciones modernas del poema: una en JoAQuín Antonio PeñaLOSA, Flor y canto de poesía guadalupana. Siglo XVII, Editorial Jus, México, 1987, pp. 73-146. La otra es la reciente edición comentada: F. DE CASTRO, La octava Maravilla y sin segundo milagro de México, perpetuado en las rosas de Guadalupe y escrito heroicamente en octavas, nueva ed. y comento de A. Pérez-Amador Adam, F.C.E., México, 2012. Cuando me refiera a los comentarios de Pérez-Amador, sólo indicaré el número de página).

${ }^{6}$ Recóndita relación entre el cerro y el mito de Opis (oct. 3). De lejos, el cerro figura la torre de Faro y su esterilidad remite a la sed de Tántalo (oct. 5). Por allí nunca pasean Flora o Vertuno (oct. 9). 
Aquí un sábado (día había de ser consagrado a María) pasaba un indio, si recién convertido, venturosamente advertido, pues oyendo músicas dulces, acordes consonancias, entonaciones uniformes, realzados contrapuntos y sonorosos acentos, reparando que no eran de ruiseñores, calandrias o filomenas, ni de sus pájaros conocidos, parleros gorriones, silgueros apacibles o celebrados cenzontles, se detuvo suspenso y se atajó elevado (ff. $19 \mathrm{r}^{\circ}-19 \mathrm{v}^{\circ}$ ).

La octava maravilla y sin segundo milagro imagina entonces que antes de las mariofanías el cerro sólo estaba habitado por las aves funestas de la tradición clásica, convirtiéndose el día de la primera manifestación en una inédita capilla celeste. La construcción de este novedoso y magnífico claroscuro musical permitirá acercarse y examinar ciertas formas de asimilación y apropiación de la poética gongorina, en particular el empleo de la perífrasis y de la alusión mitológica.

Una vez finalizada la descripción física del Tepeyac (1-11), el poema proyecta su fúnebre soplo:

El aire corresponde a su terreno, y cual aquél de amenidad errante, éste de fija variedad ajeno; despoblada estación, vaga o constante, de verde copa o de clarín ameno que brinde al alba o sus victorias cante. Sitio al fin de alto a bajo yermo y mudo, no más de pluma que de voz desnudo

(III, 12).

[El aire se corresponde con su terreno, si el primero carece (= ajeno) de amenidad errante, el segundo carece (= ajeno) de fija variedad. Es una estación despoblada, vaga o constante, sin verde copa que brinde al alba y sin clarines amenos que canten su victoria. Sitio, en suma, de alto a bajo yermo y mudo, no más desnudo de pluma que de voz.]

Para entrar al mundo de las alusiones y elusiones, nada mejor que empezar por la metáfora, atendiendo a las dos sustituciones de los versos 2 y 3 que organizan la octava, "amenidad errante" y "fija variedad". Un lector contemporáneo no debió hallar aquí ningún ripio, ambas metáforas, si bien no son planas, están lejísimos de ser "oscuras". El primer sintagma se refiere a los pájaros, pero no a cualesquiera, sino a los cantores: 'amenidad' remite 
a su voz adornada y fecunda, 'errante' a su vuelo sin punto fijo de un lado a otro. Esto parece muy sencillo, pero no lo es tanto. Castro emplea un recurso característico de Góngora: la restricción semántica que impone el adjetivo, en este caso, 'errante'7. Es precisamente dicha restricción la que señala qué sentido tiene el sustantivo 'amenidad', la que permite entenderlo como "la variedad y fecundidad en los discursos y el adorno de la erudición con que se viste y exornan" (Dicc. Aut.). Si se reduce el sustantivo a su primera acepción, a saber, "la frondosidad y hermosa vista que componen la muchedumbre de árboles, plantas, hierbas y flores en el campo", se desbarata en parte la metáfora y se crea una confusión: un lugar ameno difícilmente pueda ser 'errante', no así el 'discurso adornado', el canto de los pájaros. El sintagma "fija variedad" reemplaza, si se quiere, a 'flores diversas': 'fijas' porque nacen y mueren en el mismo lugar, 'variedad' por sus numerosos colores y especies. Por lo pronto, importará retener la relación semántica que tienen los adjetivos 'fija' y 'errante'.

El segundo período de la octava (4-6) agrupa similares metáforas en un verso bimembre (5): los "clarines amenos" sustituyen de nueva cuenta a 'pájaros melodiosos' y "verde copa" a 'árbol frondoso'. Planas y poco originales, incluso "verde copa" proviene de Lope por medio de Calderón, ambas metáforas seleccionan sus respectivos verbos, distribuidos de forma simétrica en el verso siguiente (6): los "clarines amenos" 'cantan' cuando empieza a salir el sol; los árboles, en tanto 'copas', 'brindan' al alba con el rocío de sus verdes ramajes. La octava instaura un tiempo concreto, el amanecer, el alba que nunca llega a la 'despoblada estación' del cerro. Ahora bien, esa despoblada estación puede ser "vaga" o "constante", adjetivos que remiten a la dualidad 'fija-errante'8 . Las correlaciones semánticas 'errante-vaga' y 'fija-constante' establecen, por tanto, un insólito contraste por semejanza: por su clima vago y constante, el Tepeyac carece de fijas flores y de errantes pájaros. Dicho con otras pala-

7 Véase Antonio Carreira, "La especificidad del lenguaje gongorino", BHi, 112 (2010), 89-112.

8 "VAGo, GA. adj. Lo que anda de una parte a otra sin determinación alguna... Vale también inquieto, sin consistencia u estabilidad" (Dicc. Aut.). "Errante. part. act. del verbo Errar. Errado, sin acierto, inconstante, vagante y nada seguro. Lat. Vagus, Erraticus, Inconstans" (Dicc. Aut.). "Fijo. adj. Firme, seguro y cierto" (Dicc. Aut.). "Constante. adj. Firme, estable, permanente" (Dicc. Aut.). 
bras, el cerro se contrapone a las flores y al canto mediante una especie de paradoja adjetiva que los enfrenta por aquellos atributos que comparten.

La ausencia de canto es el eje de la próxima octava:

Ni allí la que polingüe honor del viento

llama el griego por diestra imitadora

del universo colorido acento

-ave que el viento américo no ignora,

la cien voces por digno cognomento-, ${ }^{9}$

la gana de llorar quitó a la Aurora

ni se la puso de reír al alba

viéndose picos muda y plumas calva

(III, 13).

[Ni siquiera allí el ave (= la) que llama el griego polilingüe honor del viento por diestra imitadora del universo acento colorido -ave que no ignora el viento americano, conocida aquí como el ave de cien voces (= la cien voces por digno cognomento)- le quitó las ganas de llorar a la Aurora (con su dulce canto) o bien incitó a reír al alba, viéndose (cuando se acerca al Tepeyac) con su pico mudo y con sus plumas calvas.]

Castro recurre a una perífrasis continua o, para ser exactos, a una doble perífrasis. La primera comprende los versos 1-3, la segunda el inciso de los versos 4-5. Según Alberto Pérez-Amador, el ave 'polingüe' o políglota sería la alondra, así descrita por Homero, "el griego" (p. 357). Desafortunadamente, olvida señalar el respectivo pasaje homérico o la posible poliantea empleada por Castro. Mientras no se localice esta supuesta fuente, lo más sensato será entender 'el griego' en sentido genérico ('los griegos') y no circunscrito al cantor de la Ilíada. Esto por un lado. Por otro, la identidad del ave no queda del todo clara y puede ser tanto la alondra como la calandria o el ruiseñor, aves afines y que remedan el canto de sus pares, el 'universo colorido acento'. La segunda perífrasis permite ajustar la palabra eludida, puesto que el pájaro americano de muchas (= cien) voces es el cenzontle, nombre náhuatl que significa 'cuatrocientas voces', precisamente por su gran capacidad imitativa ${ }^{10}$. Vie-

9 Princeps: "la cien veces por digno cognomento-". Justifico la lección "voces" por "veces" a continuación.

10 "Centzontlatole (pues éste es el verdadero nombre y el de centzontli se usa para abreviar) quiere decir que tiene infinitas voces. Los mexicanos 
ne muy a cuento recordar que los novohispanos compararon el múltiple canto del cenzontle con el múltiple canto del ruiseñor, señalando incluso la preeminencia del primero. Comenta Francisco Xavier Clavijero:

...aunque no hubiese en América ruiseñores, jilgueros ni ningún otro de los que se estiman en Europa por su canto, bastaría el centzontli o polígloto para no tener nada que envidiar a ningún país del globo. Puedo asegurar a nuestros filósofos antiamericanos que cuanto dice el Dr. Hernández acerca de la superioridad de aquel pájaro con respecto al ruiseñor es la pura verdad y tan conforme a la opinión de los europeos que han estado en México como a la de los mexicanos que han estado en Europa. Además de la singular dulzura de su canto, de la prodigiosa variedad de sus sones y de la donosa propiedad de remedar las voces de animales que oye, lleva al ruiseñor la ventaja de ser mucho más común y de condición más apacible ${ }^{11}$.

Formalmente, la octava establece una comparación entre el ave europea y la mesoamericana que duplica la perífrasis. Dicho de otra manera, el nombre eludido queda cercado por una perífrasis que, a su vez, se explica o reduce mediante otra. Pero, además, la comparación perifrástica intensifica admirablemente la desolación del cerro: que allí no se oiga el ruiseñor, puede aceptarse porque a fin de cuentas es un pájaro europeo, pero que no se oiga el cenzontle, el ave americana exaltada por los naturalistas, una de las más representativas del continente y que es "mucho más común" (i.e. abunda), resulta realmente increíble. Mutatis mutandis, podría decirse que el Tepeyac es "dos veces mudo"12.

¿Por qué esta anomalía, por qué el dulce canto del ruiseñor-cenzontle no se oye en el cerro cuando amanece o, parafra-

usan la palabra centzontli (cuatrocientos), como los latinos usan las de mille y saecenta, para expresar una muchedumbre indefinida e innumerable. Conviene con el nombre mexicano el griego políglota, que le dan algunos ornitologistas modernos" (Francisco SAVErio Clavijero, Historia antigua de Mégico, trad. del italiano de José Joaquín de Mora, R. Ackermann, London, 1826 , t. 1 , p. 50 ).

11 Ibid., p. 293.

12 La lección "voces" por "veces" que propongo y justifico se desprende además de la tipografía de la $e d$. princeps, donde el sintagma "la cien veces" está resaltado con cursivas. Estas cursivas aparecen en la princeps cuando el poema emplea voces o derivaciones de voces nahuas (Tenoztlán, Tenoztlino, Teotenantzin) o cuando ofrece alguna explicación etimológica, como en el presente caso (el otro, la que ahuyenta fieras, supuesta etimología de Guadalupe). 
seando la octava, no le quita las ganas de llorar a la Aurora para hacerla reír? Los dos acusativos griegos del verso final, "viéndose picos muda y plumas calva", lo explican de una manera hiperculta: cuando se acerca al Tepeyac, el ave queda muda en relación con su pico y calva en relación con sus plumas ${ }^{13}$; se transforma, como anota Pérez-Amador, en un murciélago (p. 357). El acusativo griego, en este caso, no es puramente ornamental, mero lucimiento retórico: funciona también como cláusula explicativa y concentra el sentido global de la octava, la cual fluye sin pausa y sin rodeos hacia ese último verso que, ahora sí, altera la sintaxis como el cerro altera al pájaro cantor por excelencia ${ }^{14}$. En este orden, la metamorfosis del ruiseñor-cenzontle anticipa las tradicionales aves nocturnas que ensombrecen el cerro con su destemplada melodía:

El negro, cuando más, de inmunda cuerva graznido oye la tarde en pos del nido o la noche por líquida Minerva al allí en vano pájaro perdido; al abrigo, no al pasto, la caterva convoya de su coro anochecido, Ascálafo a su voz siempre insüave, agudo gima o se lamente grave.

Del monstruo alado, pájaro sin pluma -imagen del doméstico cuádrupe que en bulto poco suma inquietud suma-, la mal pïante turba el aire tupe, cansa el oído y a la noche abruma, -cuidado del antiguo Guadalupe-, con la música infausta para el día que en él hizo estación santa María

(III, 14-15).

13 Sobre el acusativo griego, véase Dámaso Alonso, La lengua poética de Góngora (parte primera, corregida), Silvio Aguirre impresor (RFH, anejo 20), Madrid, 1950, pp. 162-167. En el ejemplo de Castro, los que originan el acusativo griego de relación son los adjetivos ("muda", "calva"), que en vez de concordar con el sustantivo que califican ("picos", "plumas") lo hacen con el sustantivo "ave".

14 Señala Martha Lilia Tenorio: "Quizá los dos procedimientos más notables en Castro, por frecuencia, por intención estética y por contraste frente al resto de los gongoristas novohispanos, sean los cultismos y el acusativo griego" (El gongorismo en Nueva España. Ensayo de restitución, El Colegio de México, México, 2013, p. 100). 
[A lo sumo (= cuando más), la tarde oye el negro graznido de la cuerva que busca su nido (= en pos del nido) o la noche [oye] al pájaro, allí perdido en vano, que busca la líquida Minerva. Ascálafo, con [= a] su voz siempre insuave, agudo gima o se lamente grave, convoya la caterva al abrigo de su coro anochecido, y no adonde está el alimento (= no al pasto).]

[Temor del antiguo Guadalupe, la mal pïante turba del monstruo alado, pájaro sin pluma -imagen del doméstico cuádrupe que suma en poco bulto suma inquietud- tupe el aire, cansa al oído y a la noche abruma con la música infausta para el día que en el cerro hizo estación Santa María.]

Ambas octavas son un excelente ejemplo de imitación gongorina. Castro elabora y amplifica el pareado que describe la cueva de Polifemo, tan sombría que allí puede verse a la "infame turba de nocturnas aves / gimiendo tristes y volando graves" (V). Salcedo Coronel comenta: "llama infame las nocturnas aves porque según Ovidio las causas de su transformación fueron infames" y a continuación refiere las historias de Ascálafo (el búho), de Nictimene (la lechuza) y de las "mujeres que despreciaron la religión de Baco..." (los murciélagos), esto es, tres de los cuatro pájaros aludidos en las octavas de Castro, pájaros cuya ignominia es tan grande que temen salir durante el día ${ }^{15}$. Si bien las cuervas no forman parte de este repertorio, ellas aparecen relacionadas con la oscuridad en la magnífica escena de cetrería que describe Góngora en la Soledad segunda, donde los cazadores las sueltan a mediodía para que nublen el cielo y hagan salir al búho-Ascálafo (vv. 883-901). Castro funde ambas reminiscencias gongorinas y presenta las cuervas en primer término en la medida que ellas anuncian la noche que ampara a la infame turba. De hecho, la contigüidad tarde-noche la señala la primera parte de la octava 14 con el zeugma del verbo 'oír', el cual enlaza ambos períodos: 'la tarde oye a tal ave o la noche oye a tal otra'.

De la referencia plana de las cuervas el poema transita a las referencias oblicuas del 'idiolecto mitológico':

Para la poesía renacentista, heredera en esto como en tantas cosas de la poesía latina, los álamos son Helíades, el rocío lágrimas de

15 García de Salcedo Coronel, El Polifemo de Don Luis de Góngora comentado por..., Madrid, 1629, ff. $12 \mathrm{r}^{\circ}-13 \mathrm{r}^{\circ}$. Ascálafo fue trasformado por delator, Nictimene por incesto y las tres hermanas por impías. 
la Aurora, y el alba la esposa de Titón. Góngora y sus seguidores escriben esta lengua, como en un dialecto del castellano, pero la misma curiosa inflexión que recibe el castellano en manos de Góngora, transformándose en algo ni del todo ajeno ni del todo propio, en una fascinante y familiar extrañeza, esa misma inflexión la recibe el dialecto mitológico, lengua erudita, lengua sagrada, que distingue al poeta del vulgo ${ }^{16}$.

En primer lugar, el verso 3 de la octava 14 sustituye nominativamente la voz 'oliva' por la voz 'Minerva', puesto que el fruto, descubierto por la diosa, era uno de sus atributos ${ }^{17}$. Esta sustitución, poco frecuente, esconde a su vez una metáfora: líquida Minerva $=$ líquida oliva $=$ aceite $^{18}$. Y según una creencia popular, el pájaro que de noche bebía el aceite consagrado de los templos era la lechuza ${ }^{19}$, la cual en el presente pasaje deambula "en vano", porque en el Tepeyac no hay ninguna iglesia. De una forma muy gongorina, Castro alude velada y sintéticamente a la lechuza mediante una de sus particularidades, en este caso una de sus acciones ${ }^{20}$. Incluso podría decirse que toda la perífrasis depende del sustituyente: de forma directa, reemplaza a oliva; de forma indirecta, comprehende el término omitido, toda vez que la lechuza es el ave de Minerva.

La inflexión mitológica gana en complejidad conforme avanza la octava, como si la oscuridad del Tepeyac emanara de la oscuridad expresiva. Se dirá con razón que Ascálafo por búho era parte del repertorio culto y a esa altura una sustitución lexicalizada. Conviene, sin embargo, transcribir de nueva cuenta parte de la octava 14 para percibir cómo la referencia mitológica traba el concepto:

16 Mercedes Blanco, "La estela del Polifemo o el florecimiento de la fábula barroca (1613-1624)", Lectura y Signo, 2010, núm. 5, p. 43.

17 "...oleaeque Minerua/ inuentrix" (Virgilio, Geórgicas, I, vv. 18-19).

18 Para sor Juana, el aceite de oliva será 'el fruto de prensas agravado', precisamente porque las prensas licuan la oliva.

19 En su comentario al Primero sueño (c. 1700), observa Pedro Álvarez de Lugo: "Perdiendo (en ver autores) el aceite y el trabajo (como dicen vulgarmente), no he hallado que sea amiga del aceite la lechuza, para entrarse en los templos a agotar a las lámparas el suyo. Pero vulgarmente corre que vuela hacia ellas y las deja extinguidas" (apud Andrés SÁnchez Robayna, Para leer el "Primero sueño" de sor Juana Inés de la Cruz, F.C.E., México, 1990, p. 74).

20 Así, por ejemplo, la archiconocida alusión al toro como "el mentido robador de Europa" al inicio de la Soledad primera. 
...o la noche por líquida Minerva

al allí en vano pájaro perdido;

al abrigo, no al pasto, la caterva convoya de su coro anochecido, Ascálafo a su voz siempre insüave, agudo gima o se lamente grave.

El período en cuestión (5-8) permite dos posibles reconstrucciones:

1) Ascálafo, con $[=a]$ su voz siempre insuave, agudo gima o se lamente grave, convoya la caterva de su coro anochecido al abrigo, no al pasto.

2) Ascálafo, con $[=a]$ su voz siempre insuave, agudo gima o se lamente grave, convoya la caterva al abrigo de su coro anochecido, no al pasto.

Como ya se habrá advertido, el eje del problema es la posición del sintagma "su coro anochecido". Según la primera lectura, el posesivo 'su' remite "al allí en vano pájaro perdido" del verso anterior, es decir, a la lechuza. De acuerdo con esta lectura, Ascálafo conduce la caterva del coro anochecido de las lechuzas al reparo (= abrigo) de otro sitio, ya que no encuentran el alimento (= el pasto) de las lámparas ${ }^{21}$. En la segunda reconstrucción, el posesivo 'su' se refiere a Ascálafo. Según Dicc. Aut., 'coro' significa tanto el conjunto de voces que cantan como el espacio del templo donde "asisten los clérigos o los religiosos para cantar las horas canónicas y celebrar los divinos oficios". Esta última acepción revela un concepto mucho más ajustado: Ascálafo acompaña o conduce la caterva (las lechuzas, acaso también las cuervas) al abrigo del templo (= coro) donde él canta con "su voz siempre insuave", ya que no las puede conducir al templo sagrado donde está el aceite. Como Ascálafo habita en el inframundo, el coro, el templo donde canta no puede estar sino allí; por eso, es un "coro anochecido", porque no recibe la luz. Sinuosamente, el 'negro graznido' de las cuervas conduce al sombrío inframundo, donde en la versión cristiana moran los pecadores, esos

${ }^{21}$ Ésta pareciera ser la interpretación de Alfonso Méndez Plancarte: “Sólo se oye, en la tarde, 'el negro graznido' de los cuervos (admirable sinestesia o sinécdoque); y luego, 'el coro anochecido de la lechuza' (el pájaro 'perdido por líquida Minerva', codicioso del aceite de oliva; pero allí, 'en vano', por no haber en la cercanía ningún templo en cuyas lámparas lo beba)...” (Poetas novohispanos. Segundo siglo, UNAM, México, 1994, t. 1, p. 245). 
mismos que por su delación, incesto e impiedad fueron transformados en las funestas aves que sólo aparecen durante la noche. En el último verso de la octava, Castro remata la metáfora musical imitando el célebre "gimiendo tristes y volando graves". Si bien respeta la obligada bimembración y hasta la acentuación en 4 y 8 , su verso no es simétrico, sino especular: "agudo gima o se lamente grave". La posición al principio y al final de adjetivos antónimos -elaboración del 'mucho-poco' gongorino, que aparece en La octava maravilla y sin segundo milagro con múltiples variantes- sugiere un canto pausado y aburrido, pesadumbre que en el Primero sueño se convertirá en la torpe mensura perezosa que adormece al mismo viento (vv. 60-64).

Sobre ese canto denso, tedioso, soporífero insiste la próxima octava (15), incorporando el "monstruo alado, pájaro sin plumas" a la capilla pavorosa, perífrasis que retoma la descripción del murciélago anticipada en el pareado de la estrofa 13. El inciso 2-3 establece una familiar correspondencia entre el murciélago y el ratón, ciertamente aludido como: 'el doméstico cuadrúpedo' (= cuádrupe). Aquí la doble perífrasis se acerca en grado sumo a la poética gongorina, a ese aislamiento del objeto de la "confusión de contingencias" (D. Alonso). Castro no quiere que el lector imagine un simple murciélago, un simple "monstruo alado, pájaro sin plumas", quiere que a esa imagen se sobreponga la del ratón, ese "animal sucio que suele engendrarse de la corrupción" (Covarrubias) y que, por tanto, "en poco bulto suma inquietud suma". Siendo así, la analogía implica un intercambio de propiedades y el espacio corrupto y pavoroso que procrea al ratón-murciélago se asimila con el Tepeyac. La amplificación y el desdoblamiento del pareado gongorino concluyen con la irresistible cuanto fatal tentación de imitar el endecasílabo "infame turba de noctumas aves" mediante el endecasílabo "la mal piante turba el aire tupe". Parafraseando a D. Alonso, la genialidad de Góngora es insuperable; con todo, la aglutinación de las dentales y la intencional cacofonía 'te-tur' del verso de Castro remedan y sugieren el áspero chillido del murciélago.

Una vez descrito el sombrío Tepeyac, el poema transita hacia la primera mariofanía, indicando día, mes y año mediante una rebuscada perífrasis cronológica que desarticula el numeral:

Nueve auroras el último hijo hacía de los doce que a Etesio dio la Luna; quince y un tercio aquel siglo cumplía 
desde el día en que hacer le plugo cuna y aun cama al que enfermó su valentía por ceder en salud más oportuna, a la humana epidemia sol eterno, desmintiendo al nacer noche e hibierno (III, 21).

\section{Explica Pérez-Amador:}

El último de los meses del año, es decir, diciembre, el último de los doce hijos que en la mitología griega engendró la Luna con Etesio, contaba nueve días. Entonces se contaban ya quince siglos y treinta y tres años desde el día en que le pareció bien nacer [= hacer cuna] e inclusive morir [= hacer cama] al que enfermó su valentía por dar mejor salud, es decir Cristo, el cual es un sol eterno que negó la oscuridad [= noche] y la muerte [= invierno] en el momento que decidió nacer dentro de la humana muchedumbre [= epidemia] (p. 362).

En una primera lectura, la paráfrasis no tendría nada objetable; empero, al confrontarla detenidamente con la octava se verifica un leve descuido en la traducción de la voz 'epidemia' por 'muchedumbre', sinonimia difícil de explicar léxica o semánticamente y que, además, desarticula en parte el concepto progresivo. En sintonía con las correspondencias médicas (enfermar-salud), el sintagma 'humana epidemia' se refiere al pecado original: si Cristo enfermó, esto es, si mezcló su naturaleza divina con la naturaleza humana, fue para encarnar y remediar (= sanar) así la primera culpa (= la humana epidemia); serie semántica que encierra toda la noción del pecado como infición. Por lo demás, el último verso, "desmintiendo al nacer noche e hibierno", posee un sentido literal -histórico si se quiere-, en la medida que Jesucristo habría nacido en diciembre (el invierno) y, según el credo cristiano, en la fosca y dilatada noche del paganismo (noche = pecado). El 'mundo' antes de la encarnación se refracta en el Tepeyac antes de las apariciones (invierno - noche - pecado). En este sentido, la perífrasis para indicar el año 1531 por medio de Jesucristo preludia, en una especie de prolepsis, la acción redentora de la Guadalupana, quien traerá la luz al Tepeyac y desmentirá su perpetuo invierno brotando flores. Relación determinante para descifrar la próxima octava que puntualiza la hora de la primera manifestación: 
Tres de sus doce la solar contaba majestad, ninfas de reloj sin mano, y entre las muertas, desde que doraba su matutina luz el meridiano la del diciembre aurora que a la octava se siguió del origen mariano; tal a tal de aquel mes estaba el día con la hora que a su sol fiel incumbía (III, 21-22).

Pérez-Amador:

La majestad solar contaba, sin necesidad de consultar las manecillas de un reloj, pasada [= muerta] la tercera de las doce horas [ninfas] desde el momento en que su luz alcanzó el mediodía de aquella jornada, que seguía al octavo día decembrino, día de la festividad de la Inmaculada Concepción de María [día del origen mariano]. Tal era la hora, el día y el mes que con precisión le tocaba a su sol (p. 363).

De ser así, la primera aparición guadalupana habría sucedido, según Castro, después del mediodía. Ahora bien: ¿cuál es el cómputo horario que está en juego en la octava y que permite establecer de una manera poco llana la hora de la mariofanía? Sin duda, el cómputo romano que distinguía entre doce horas diurnas y doce nocturnas, mismo que, por lo demás, empleara antes el poeta para cifrar la perpetua luz del paraíso terrenal (canto II, octavas 26-28). Las doce horas diarias comprendían sobre esclarecerlo-, el tiempo que el sol iluminaba la tierra y la primera hora empezaba con el amanecer. En consecuencia, si al pie de la letra la octava dice que "la majestad solar contaba tres de sus doce horas" al momento de la aparición, sólo puede inferirse que era la hora tercia; esto es, no mucho después de la salida del sol, la media mañana, entre las 8 y las 9 para presumir exactitud, considerando que en invierno amanece alrededor de las 6. Pérez-Amador supone que la hora tercera sigue al mediodía, porque le otorga a la voz 'meridiano' su sentido etimológico (de meridies: mediodía) y no su sentido contextual o traslaticio de cielo, espacio, horizonte, etc. ${ }^{22}$ Además, pasa por alto que

22 Podría incluso agregarse que la octava distribuye términos afines al arte de la relojería: la 'mano' o manecilla de los relojes modernos y el 'meridiano' de los relojes solares, llamado así por los romanos, porque era el eje que marcaba precisamente el mediodía. Podría pensarse además que 
este sustantivo está cercado por el sintagma "luz matutina" y por el término "aurora", los cuales desaparecen llamativamente en la prosificación. Aclarado este punto, surge de forma inevitable otra incógnita: ¿en qué se apoya Castro para afirmar que la primera aparición fue a la hora tercia? Sánchez nada dice al respecto, tampoco Mateo de la Cruz. El relato de Becerra Tanco, en cambio, señala que Juan Diego llegó al pie del cerro "al romper del alba"; de modo que la mariofanía guadalupana se corresponde con la llegada de la aurora, con todo lo que esto representa en el plano simbólico. Aunque la relación Virgen-Aurora está latente en el poema, no explica esa misteriosa hora tercera. Para ello, hay que remitirse a la vulgata del evangelio según san Marcos, en concreto al capítulo 15 donde se narran los últimos actos de Jesucristo y su crucifixión (cursivas mías):

Et perducunt illum in Golgotha locum, quod est interpretatum Calvariae locus.

Et dabant ei myrrhatum vinum; ille autem non accepit.

Et crucifigunt eum, dividunt vestimenta eius, mittentes sortem super eis, quis quid tolleret.

Erat autem hora tertia, et crucifixerunt eum.

Como la Pasión, el sufrimiento en la cruz por el pecado de todos los hombres, el tránsito más importante y definitivo para la salvación de las almas, comenzó a la hora tertia, Castro imaginó que la aparición guadalupana, debido a la redención que supone para el Nuevo Mundo, sucedió a la misma hora. Se sella así el vínculo que la octava anterior sugería entre la venida del salvador y las mariofanías del Tepeyac. Poéticamente, sorprende la habilidad de Castro para enlazar las dos figuras en el curso de dos octavas que en apariencia sólo estarían cifrando el sábado 9 de diciembre de 1531; perífrasis numeral que concierta a las máximas figuras del cristianismo con las del panteón grecorromano (el origen mítico de los meses junto al nacimiento, muerte y pasión de Jesucristo; las horas como ninfas hijas de Júpiter junto a la Inmaculada Concepción). Castro elabora y proyecta así un punto cardinal del pensamiento guadalupano destacado en su momento por Francisco de la Maza:

la majestad solar no cuenta las tres horas con mano de reloj, porque las calcula en la sombra del reloj solar. 
Dios creó al Viejo Mundo para que naciese Adán, "la primera imagen suya", y luego para que Cristo, el "segundo Adán", según la tradición mística, fuese crucificado sobre la tumba del primer hombre para dar fe y redención al género humano. Mas la segunda Eva aún no había nacido; esperaba un nuevo Paraíso. Y viene a cuento recordar que a las tierras encontradas por Colón se les llamó paraíso y esa palabra andaba en boca y plumas de los primeros cronistas de Indias. Ahora bien, si en un "paraíso", es decir, en una especie de segunda creación, se aparece o se presenta María, resulta precisamente la "segunda Eva", la verdadera corredentora que viene a dar fe y redención al Nuevo Mundo ${ }^{23}$.

Esa luz matutina, 'esa aurora que sigue a la octava del origen mariano' (i.e. la Inmaculada Concepción), comienza a alumbrar el Nuevo Mundo mientras aguarda la llegada de Juan Diego, quien al pasar por el cerro escucha sorprendido las harpadas lenguas que allí repican, precisamente porque están saludando la llegada de la verdadera Aurora, de la Virgen de Guadalupe ${ }^{24}$ :
Cuando al dichoso Juan, por escogido
precursor de la rosa nazarea, yendo pies suelto y ánimo encogido rumbo en demanda de su fiel tarea por aquel entre lago y monte ejido, pasos, alma y camino le saltea gente, si de los hombres, por canora pasible cosa, entonces cazadora

(III, 21-23).

[Cuando al dichoso Juan -elegido precursor de la rosa nazarena, que velozmente y con el ánimo encogido pasaba por aquel paraje situado entre el lago y el cerro en dirección a Tlatelolco, donde iba a recibir la doctrina que allí impartían los franciscanos (= rumbo en demanda de su fiel tarea)- lo embiste (= saltea) un

${ }^{23}$ Francisco de la Maza, El guadalupanismo mexicano, F.C.E., México, 1984 , p. 58.

${ }^{24}$ Hasta donde pude indagar, antes de Castro sólo desarrolla la serie analógica Aurora-María-pájaros un villancico anónimo de 1669 con música de Francisco López Capillas: "Músicos pajarillos/ alegres cantan,/ y al rayito del sol/ que brilla, que luce, que halaga,/ saludan al alba./ Un pasajero admirado/ curioso a escuchar se para/ y repara/ en que una voz lo ha llamado./ A la cumbre del monte/ volando sube/ y a sus ojos el alba/ se le descubre" (apud JoAQUín Antonio Peñalosa, Flor y canto de poesía guadalupana. Siglo XVIII, Editorial Jus, México, 1988, p. 309). 
grupo de gente, por canora pasible cosa, si entonces cazadora de los hombres.]

El verso 3 armoniza de nueva cuenta, y gracias a la bimembración, los adjetivos opuestos "suelto" y "encogido"; a su vez, cada uno de los segmentos del verso queda delimitado por su respectivo acusativo griego, donde se concentra, además, la plasticidad de la imagen: Juan Diego caminaba ligero en cuanto a sus pies y apocado en cuanto a su estado de ánimo; es decir, la prisa de su andar lo dejaba sin aliento. El pareado por su parte echa mano de la fórmula A si B, alterada por el hipérbaton: 'a Juan Diego lo saltea gente, por canora pasible cosa, si entonces cazadora de los hombres'. Si la caza supone la privación de la libertad, la que practican estos cazadores puede sufrirse porque atraen a las presas con su armonioso canto. Imposible no pensar en el melódico y subyugante de las sirenas. Pero como enseguida se verá, Castro orienta y desorienta al lector y la potencial reminiscencia de las sirenas quedará descartada. Con todo, ese canto preludia el despliegue del infaltable mundo mítico de la poesía culta:

Por donde más los ojos exaspera al caminante de la cumbre el ceño -cuales no en su oceana primavera o estación fortunada escuchó isleño, no el Pindo cuando es tumbo su riberapor el diciembre en facistol despeño voces el indio oyó, con cuyo acento miente otra vez de Anfión el instrumento (III, 24).

[Por donde más la imponente y áspera cumbre (= el ceño) exaspera los ojos al caminante en el invierno (= por el diciembre), el indio oyó un coro de voces que desde allí bajaba (= facistol despeño), tan dulce que bien pudiera decirse que por segunda vez sonaba la lira de Anfión. Semejante melodía no la oyó nunca el habitante de las islas afortunadas donde es eterna la primavera, tampoco las riberas del Pindo cuando hasta allí baja el estrepitoso canto de las musas (= cuando es tumbo su ribera).]

Así como la capilla pavorosa del Tepeyac se ilustraba mediante las míticas aves funestas, el numeroso y atrapante coro que oye Juan Diego se ilustra mediante la mítica lira de Anfión, famosa porque encantaba hasta las mismas piedras. Y si el pasaje de las 
aves amplificaba el pareado del Polifemo, el último verso de la presente octava remite a cualquier lector de las Soledades al inicio de la primera, al endecasílabo que define el mísero gemido del náufrago como "segundo de Arión dulce instrumento" -y sobra recordar que los lectores contemporáneos del poema estaban por demás versados en las obras mayores de Góngora. En estos ocho versos, Castro ha transformado el ronco Tepeyac en un sitio armonioso, donde se escucha un canto cual nunca oyeron las riberas del Pindo cuando hasta allí desciende el estrepitoso canto de las musas ("cuando es tumbo su ribera") o cual nunca escucharon los habitantes de esas jubilosas islas donde es perpetua la primavera. Esta isla acaso pueda identificarse con las islas afortunadas, los campos Elíseos donde descansan las almas de los justos, imagen pagana del paraíso judeocristiano. Pero la reminiscencia gongorina del último verso evoca, por defecto, la ínsula donde arriba -en primavera, por cierto- el peregrino de las Soledades, esa isla de la edad de oro donde sus habitantes entonan epitalamios, himeneos y cantos amebeos ${ }^{25}$.

La correspondencia Pindo-Tepeyac determina o, mejor, atrae la alusión mitológica ${ }^{26}$ :

No así retada en la campaña amena por aquella su Apolo numerosa, que en pocas fauces tantos coros llena, de aladas musas tropa invidiosa oyendo su garganta en voz ajena de la suya juzgó más ingeniosa ${ }^{27}$, cuando habrá alguna que el vital aliento ${ }^{28}$ perdió intentado inaccesible acento

[Al oír su voz en garganta ajena y retada en la (ahora) campaña amena (del Tepeyac) por la lira armoniosa de Anfión (= su Apolo numerosa), aquella tropa envidiosa de aladas musas, que tantos coros llena en pocas fauces, no juzgó que esa lira fuera superior a su propio canto (= no así de la suya juzgó más ingeniosa), aun-

${ }^{25}$ Me parece excesiva la identificación de esta isla con México-Tenochtitlan, tal como sostiene sin dar ninguna explicación Pérez-Amador.

${ }^{26}$ Es decir: el coro del Tepeyac desciende ('se despeña') de la cumbre como desciende desde el Pindo el coro de las musas o bien el canto de Apolo.

27 Princeps: "de la suya jugó más ingeniosa".

28 Princeps: "cuando hará alguna que el vital aliento". 
que (= cuando) alguna, que el vital aliento perdió, habrá (acaso) intentado imitar (su) inaccesible acento.]

La importancia del modelo o del intertexto -en este caso las Soledades- resulta fundamental para comprender la presente octava, evitando así una interpretación equívoca propiciada por la anfibología de los versos 3 y 4 . Desatado el hipérbaton, queda: 'aquella tropa envidiosa de aladas musas que tantos coros llena en pocas fauces'. En principio, pareciera que tales versos tienen un sentido literal y que se refieren a las musas y a su capacidad para "lograr con sólo nueve bocas crear tantos coros", como entiende PérezAmador (p. 365). ¿Tienen alas las hijas de Júpiter y la Memoria? Se diría que no. El sintagma "aladas musas" proviene de la Soledad segunda, en concreto del pasaje que recrea el locus donde comen el peregrino y el anciano pescador (vv. 349-360, cursivas mías):

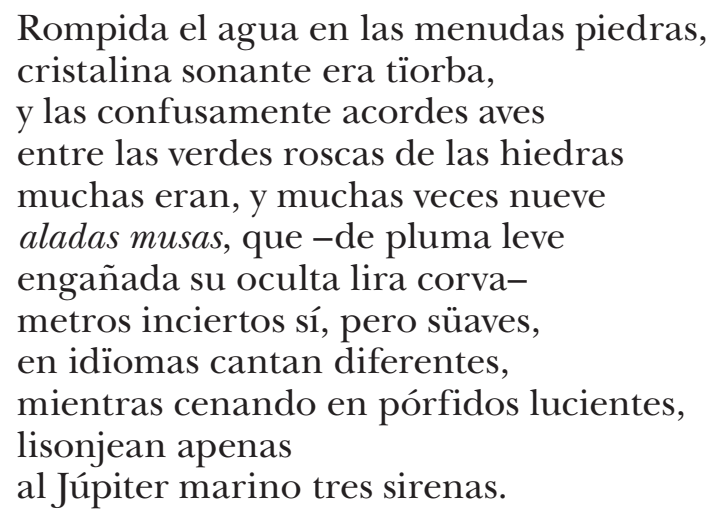

Para el perspicaz andaluz, la dulzura del canto de los pájaros puede compararse con la dulzura del canto de las musas, y como los pájaros tienen alas, nada más justo y poético que llamarlos "aladas musas". En la octava de Castro, el mismo sintagma tiene idéntico sentido traslaticio, hecho que se corrobora al observar que el endecasílabo "que en pocas fauces tantos coros llena” elabora, apelando al gongorino 'poco-mucho', un tópico recurrente de la poesía áurea, si no de la tradición occidental: el bello y potente canto de las aves a pesar de su pequeño pecho o tamaño ${ }^{29}$. Resumiendo: la octava alude muy veladamente al mito

29 Así, por ejemplo, en la letrilla de Quevedo "Flor que cantas, flor que vuelas" (núm. 206, ed. J.M. Blecua): "En un átomo de pluma / ¿cómo tal concento cabe? / ¿Cómo se esconde en una ave / cuanto el contrapunto 
de las piérides, las nueve hermanas que osaron competir con las musas y que, derrotadas, fueron convertidas en urracas ${ }^{30}$. De esta manera, como en la octava anterior el Tepeyac era un nuevo y mejor Pindo, en la presente el poeta imagina que un grupo de pájaros, desafiado por el sonido que bajaba del cerro, por la lira de Anfión (= 'tropa de aladas musas retada en la campaña amena por su Apolo numerosa') ${ }^{31}$, envidioso cual piérides, juzgó que tal canto no superaba al suyo, si bien alguno perdió su voz al intentar imitarlo.

La próxima estrofa insiste sobre la supremacía melódica del Tepeyac:

Como de bien picadas a porfía dulces aves del pico a la impaciencia, la acorde sí, aunque adversa melodía, desde aquella cerril o sea eminencia descendiendo, suspenso conducía, con poderosa más dulce violencia que la sonada lira del tebano, no al llano el monte, sino al monte el llano

(III, 26).

[La melodía -acorde aunque adversa, como si compitiera con [=a porfía] la de las dulces aves cuando hieren el aire (= picadas) con la impaciencia de su canto (= pico)-, descendiendo desde aquella altura, conducía suspenso el llano al monte en vez del monte al llano, (y lo conducía) con dulce violencia más poderosa que la renombrada (= sonada) lira de Anfión (= del tebano).]

El mito de Anfión que ha organizado el pasaje culmina con una clara referencia a la capacidad persuasiva de su lira: si ésta conducía las piedras hacia el llano donde se construían las mura-

suma? /... / Voz pintada, canto alado, / poco al ver, mucho al oído, / ¿dónde tienes escondido / tanto instrumento templado?"

30 Ovidio, Las metamorfosis, V, vv. 294-678.

31 Entiendo que "Apolo" sustituye nominativamente a 'lira' (como antes "Minerva” sustituía a 'oliva'), instrumento suyo por excelencia obsequiado justamente a Anfión. Según mi lectura, "numerosa" califica a Apolo por concordancia ad sensum impuesta por la rima; schema, diría NEBRIJA, "solecismo... que por alguna razón se puede escusar", apud NADINE Ly, "El orden de las palabras: orden lógico, orden analógico (la sintaxis figurativa en las Soledades)", BHi, 101 (1999), p. 22. Por tanto, en el sintagma 'su Apolo numerosa' (= su lira melodiosa), el posesivo 'su' remite al sustantivo Anfión del último verso de la octava anterior (24). 
llas de Tebas, ahora el canto de las aves persuade al camino inverso y conduce el llano al monte. El peso del verso final reposa en la bisemia del sustantivo 'llano'. Por un lado, literalmente, se refiere al campo llano, parejo, sin altos ni bajos, como si todo el terreno se movilizara hacia la cumbre del cerro. Por otro, el llano es el mismo Juan Diego, conducido con el suave son hacia el Tepeyac $^{32}$. El eco del pasaje antes citado de las Soledades regresa con el endecasílabo "la acorde sí, aunque adversa melodía", verso que remite a las "confusamente acordes aves", además de apoyarse en la inagotable fórmula sí A pero $\mathrm{B}$.

El canto mítico se dilata hasta la próxima octava:

No de la novedad más que el recreo instado el indio - pero, ¿̇a quién no instara oír do el aire nunca oyó gorjeo de alados coros música tan rara, que en sus falsas no más tuviera Orfeo con qué hacer su mentira verdad clara?del que iba al templo, al cerro, no divino menos a la sazón, guiñó camino

(III, 27).

[El indio, instado tanto de la novedad como del recreo, del camino que iba al templo se dirigió (= guiñó) hacia el camino que iba al cerro, entonces no menos divino que un templo. Pero ¿quién no hiciera así al oír, donde el aire nunca oyó gorjeo, música tan rara de alados coros, tan rara que sólo en sus tonos (= en sus falsas no más) tuviera Orfeo con que hacer clara verdad su mentira.]

Al lado de Anfión, el poema coloca a Orfeo, el otro gran liróforo de la tradición clásica que conjuraba los elementos al son de su canto. Pero conviene recordar que desde el Renacimiento Orfeo era, sobre todo, y en consonancia con su leyenda mítica, el paradigma del músico, del poeta y del sabio, autor real, incluso, de tres himnos y de las Argonáuticas órficas, textos que circula-

32 "Hombre llano, el que no tiene altiveces ni cautelas" (Covarrubias; aquí 'cautela' significa 'engaño', véase la entrada en el mismo Tesoro). Por su parte, consigna Dicc. Aut.: "Hombre llano, se llama el que es pechero y paga tributos” (y aquí “pechero' significa 'plebeyo'). Según la paráfrasis de PÉREZ-AMADOR, quien inexplicablemente pasa por alto la explícita referencia al mito de Anfión, el dulce canto que oye Juan Diego “desde aquella tosca altura no bajaba de las alturas del monte al valle, sino que el canto se situaba en las alturas del monte" (p. 365). 
ban entre los humanistas ${ }^{33}$. En definitiva, la evocación de Orfeo concluye la amplificatio que despliega el poema para figurar el extraordinario e insólito coro que bajaba del cerro, superior a cuantos ha producido el mundo grecorromano. Este sobrepujamiento se resume en la serie semántica de los versos 5-6: 'falsasmentira-verdad', donde el juego conceptual reposa en la bisemia del primer sustantivo. Según Dicc. Aut., 'falsas' "es la consonancia que por haberse dividido en tonos y semitonos sale redundante, por tener un semitono más de lo que toca a su proporción, u diminuta, por faltarle a su proporción un semitono". De modo que si Orfeo hubiera tan sólo conocido las "consonancias redundantes' que bajaban del Tepeyac, sus poemas, tanto como las fábulas que oyeron los campos y los habitantes del inframundo, no hubieran contenido puras ficciones ${ }^{34}$. Su canto hubiera sido 'verdadero' y divino como el del Tepeyac, susceptible de transformar el templo anochecido de Ascálafo en un templo resplandeciente. Y he aquí el punto: esta divinización la concentra el pareado con un giro inequívocamente gongorino, 'no menos', lítote que atenúa, o pretende atenuar, la comparación, ya que, a fin de cuentas, en ese momento el cerro era un templo más divino que la iglesia franciscana de Tlatelolco ${ }^{35}$. Hacia la visión de esa luz gloriosa transita la siguiente octava:

La falda al monte en pocos saltos prende y ganándole piedras a la cuesta, sobre la que aun de alado se defiende garzón, por erizada más que infesta ${ }^{36}$ -todo el hombre estribando en el que atiende celeste canto-, al fin se encimó cresta; de donde cuando la campaña explora se halla en vez de las aves con la Aurora

(III, 28-29).

${ }^{33}$ Natale Conti recurre en varios pasajes de su Mitología a las Argonáuticas órficas. Quevedo cita un verso de los himnos en el Epicteto.

34 En el Orfeo (1624) de Juan Pérez de Montalbán, Orfeo canta fábulas mitológicas para conjurar a los elementos.

35 Al conceder un valor esencial y determinante al canto de las aves, CAsTRO altera en parte el relato canónico de las apariciones, donde Juan Diego sube al cerro no instado por las harpadas lenguas, sino porque, una vez cesado el canto, "oyó que lo llamaban por su nombre Juan" (BEcerra TANCo, f. $1 v^{0}$ ).

36 Princeps: "garzón, por erizada más que ingesta". Propongo "infesta" a reserva de una mejor lección; "ingesta" no hace sentido o bien Castro le da una acepción derivada del latín que se me escapa. 
[La falda al monte en pocos saltos prende y ganándole piedras a la cuesta, todo el hombre estribando en el celeste canto que atiende, al fin se encimó sobre la cresta que aun se defiende de alado garzón más por erizada que por infesta. Una vez allí, cuando explora la campaña, se halla con la Aurora en vez de (hallarse con) las aves.]

El estatismo de las estrofas precedentes -¿el estatismo del mundo mítico? - cobra ahora movimiento y el poema figura el ascenso de Juan Diego en dos planos sucesivos: velozmente llega a la falda del cerro y luego asciende por la pedregosa cuesta que lleva a la cima, contigüidad determinada por la ilación sintáctica de ambos períodos. La velocidad del primer movimiento se corresponde con la fluidez sintáctica del primer endecasílabo, cuyo perfecto ritmo yámbico (oó oó oó oó oó) remeda el ritmo sin pausa de los pies ligeros ${ }^{37}$. Y si bien el segundo verso también resulta fluido, su ritmo de anapesto (ooó ooó) preanuncia una distensión y dilatación que pronto materializan las trasposiciones sintácticas comprendidas entre 3-6. La primera, la interposición de una oración de relativo que interrumpe violentamente la oración principal, la cual no termina sino hasta el verso 6: 'sobre la... cuesta al fin se encimó'. La interrupción no es gratuita: la oración de relativo ('que aun de alado garzón se defiende...') sugiere la dificultad del ascenso, ya que a las alturas donde se dirige Juan Diego no llega ni siquiera el "alado garzón”, cuya identidad no queda del todo clara. Por último, antes de completar la oración interrumpida, Castro interpone un inciso (5-6) que retarda aún más el ascenso y que, al mismo tiempo, es su razón misma: Juan Diego se apoya (= estriba) en ese canto para seguir subiendo, como si éste le diera fuerzas y lo alentara. Expandiendo la metáfora musical, el canto es una escala que permite transitar desde el llano a la cima. Salvando las distancias con el modelo, es en pasajes como éstos donde los recursos gongorinos (hipérbaton, encabalgamiento continuo, incisos oracionales) adquieren un certero valor expresivo, donde se traban plásticamente la sintaxis y la imagen poética del ascenso, la forma de la expresión y la forma del contenido.

En cuanto al sintagma "alado garzón”, Pérez-Amador entiende que se refiere a los ángeles. Para apoyar su conjetura, podría

37 GóNGORA también había empleado un perfecto yámbico para sugerir la velocidad de una pequeña embarcación: "cristal pisando azul con pies veloces" (Soledad segunda, v. 46). 
citarse una octava del inédito "Panegyris a N. S. P. Ignacio" de Alejo Cossío, profesor de gramática en el Colegio Máximo de San Pedro y San Pablo de México hacia 1737-1738, quien repite el mismo sintagma -¿lo habrá tomado de Castro?-:

Cuando alado garzón, jazmín de pluma, pasando luces, cuando el peso mueve, alivió el peso que gigante abruma, bogando en nave de argentada nieve... ${ }^{38}$.

Un reparo: la octava de Castro describe un ascenso y no un descenso; los ángeles, en tanto mensajeros, bajan, no suben. ¿Aludirá el poema al vuelo de Ícaro, quien tampoco podría remontarse a semejante altura con las alas fabricadas por su padre? ¿O será una rebuscada metáfora del águila a través de Ganimedes, forma animal adoptada por Júpiter cuando lo raptó y llamado por Góngora el "garzón de Ida" ? ${ }^{39}$ Como sea, con la aparición de la aurora mariana el cerro ha dejado de ser un lugar perjudicial, dañino y sólo conserva su naturaleza elevada adonde únicamente puede acceder el hombre elegido, 'el precursor de la rosa nazarea'. En cierto sentido, el Tepeyac se asimila con el paraíso terrenal, no sólo por su eminente altura, sino, además, porque en este preciso instante la octava relaciona las harpadas lenguas con el "celeste canto" de los ángeles.

La próxima estrofa hace explícita finalmente la identidad María-Aurora y presenta a la Virgen siempre pura (antes, durante y después del parto), toda vez que esa pureza ahora mana del Tepeyac:

Vio en forma una mujer, pero doncella fértil a par de pura; vio a María, que sobre el gremio femenil descuella más que en la triste noche alegre día; la tricolor de Juno ninfa bella de ser su templo en Argos se lucía. Quedó a su vista de un asombro ledo el indio; indio otra vez menos el miedo

(III, 29).

38 Apud Osorio Romero, Colegios y profesores jesuitas que enseñaron latín en Nueva España, UNAM, México, 1979, p. 247.

39 Pienso en esta remota posibilidad teniendo en mente el pasaje del Primero sueño, donde sor Juana propone una hipérbole similar: la altura donde se encumbra su alma es inaccesible para el vuelo del águila (vv. 327-339). 
[Vio en forma una mujer, doncella fértil a par de pura (Madre de Dios y Virgen inmaculada), vio a María que sobresale (= descuella) sobre el gremio femenil más que el alegre día sobre la triste noche. La bella ninfa tricolor de Juno se lucía de ser su templo en Argos. El indio quedó a su vista alegre del espanto (= ledo del asombro), indio otra vez menos el miedo. $]^{40}$

Nuevamente, la trascendencia que el padre Castro le confiere a ciertos elementos de las mariofanías es resaltada por las alusiones y correspondencias que establece con la tradición clásica, contenidas en este caso en los versos 5-6, los únicos 'oscuros' de toda la octava. Para un lector moderno, la alusión al arcoíris mediante la perífrasis "la bella ninfa tricolor de Juno" (6) resulta un tanto remota; para un lector contemporáneo de Castro, no lo era en absoluto. Los versados en la Eneida sabían que la mensajera de Juno, la bella ninfa, era la diosa Iris. Y en cuanto al adjetivo "tricolor", Ignacio Arellano anota que el arco "tiene tres colores en los textos áureos: rojo, verde, pálido o pajizo" y cita varios ejemplos de los autos de Calderón ${ }^{41}$. Esto por un lado. Por otro, y lo que importa examinar, entre sus múltiples simbologías, el arcoíris tiene una muy específica que proviene de la Biblia: es la señal de paz que Dios envía a Noé en el relato del diluvio, "señal de la clemencia y de la alianza que Dios hizo con los hombres"42.

40 Pérez-Amador ordena: "Vio en forma una mujer, pero doncella fértil a par de pura; vio a MARÍA, que más descuella sobre el gremio femenil que [el] alegre día en la triste noche, [tal como más descuella] la bella ninfa tricolor de Juno [que] se lucía de ser su templo en Argos [sobre el color azul obscuro llamado] indio. A su vista el indio quedó, menos el miedo, otra vez ledo del asombro". Un brevísimo comentario. El término "indio" no califica a Argos (sintácticamente imposible); tampoco existe dilogía en su iteración. Castro emplea la anadiplosis para enfatizar que el indio al principio se asustó, pero luego, al reconocer que era la Virgen, se alegró y recuperó su estado, ya sin miedo (miedo que, por lo demás, se les achacaba a los indios; por eso: "indio otra vez menos el miedo").

${ }^{41}$ Ignacio Arellano, Diccionario de los autos sacramentales de Calderón, Reichenberger-Universidad de Navarra, Kassel-Pamplona, 2000, pp. 30-31. Baste el siguiente ejemplo de El gran teatro del mundo: "A la seña que, en el cielo, / de paz hará un arco rubio / de tres colores, pajizo, / tornasolado y purpúreo..." (vv. 155-158).

42 San Jerónimo, apud Filippo Picinelli, El mundo simbólico. Los cuatro elementos, trads. Rosa Lucas González (Agua y Tierra) y Pascual Guzmán de Alba (Fuego y Aire), eds. Eloy González Bravo, Rosa Lucas González y Bárbara Skinfill Nogal, El Colegio de Michoacán, Zamora, 1999, p. 183. Pueden consultarse las numerosas simbologías del arcoíris en el mismo Picinelli. 
Los versos de Castro establecen, en este sentido, una correlación tan estrecha como rebuscada: el arco adorna ahora el templo de Argos ("de ser su templo en Argos se lucía"), patria de Juno y donde tenía ciertamente uno de sus mayores adoratorios (Iris $\rightarrow$ Juno $\rightarrow$ Argos $\rightarrow$ templo). En la octava, por defecto, Argos no puede referirse sino al Tepeyac, donde Juan Diego ve a la Virgen rodeada por los rayos del sol y las nubes, fenómeno natural que origina el arcoíris. Al menos así lo interpretó Becerra Tanco, único relato que incorpora el arcoíris en la visión que tuvo Juan Diego ${ }^{43}$ :

Oyó el indio en la cumbre del cerrillo... un canto dulce... y alzando la vista al lugar donde a su estimación se formaba el canto, vio en él una nube blanca y resplandeciente, y en el contorno de ella un hermoso arcoiris de diversos colores que se formaba de los rayos de una luz y claridad excesiva que se mostraba en medio de la nube (f. $1 \mathrm{v}^{\mathrm{o}}$, cursivas mías).

¿En qué funda Castro la correspondencia Argos-Tepeyac? Entre otras historias sobre esta legendaria ciudad, Natale Conti refiere que Juno y Neptuno se disputaron su tutela y que los ríos que por allí pasaban resolvieron el pleito en favor de la diosa. Neptuno, "encolerizado, privó de toda abundancia de aguas a aquellos que habían juzgado"; pero luego su furor cedió y devolvió el caudal a los ríos ${ }^{44}$. Es decir, al igual que el cerro que imagina Castro, Argos fue por algún tiempo tierra yerma y luego tierra fértil. En segundo lugar, se recordará, como lo hacen todos los historiadores guadalupanos desde Becerra Tanco, que en la cima del Tepeyac estaba el $c u$ de Tonantzin, como en Argos estaba el templo de Juno. Y según la versión de Castro, que sigue en este punto muy de cerca la Primavera indiana, la Guadalupana, en su primera aparición, pide que se le erija un templo en el mismo lugar donde está el templo idólatra de los sacrificios:

43 Becerra Tanco tiene en mente el texto náhuatl del Nican mopohua. Según la versión castellana de Primo Feliciano Velázquez, cuando Juan Diego llegó a la cumbre "vio a una señora, que estaba allí de pie y que le dijo que se acercara. Llegado a su presencia, se maravilló mucho de su sobrehumana grandeza: su vestidura era radiante como el sol; el risco en que posaba su planta, flechado por los resplandores, semejaba una ajorca de piedras preciosas; y relumbraba la tierra como el arco iris" (apud AlFONSO Junco, Un radical problema guadalupano, Jus, México, 1953, p. 73, cursivas mías).

44 Natale Conti, Mitología, trad., introd., notas e índices de Rosa M. Iglesias de Montiel y M. Consuelo Álvarez Morán, Universidad, Murcia, 2006, p. 643. 
Di a tu pastor, mi siervo y tu connombre, que en esta un tiempo de oblaciones fieras ara infeliz, un templo por renombre titular mío, "la que ahuyenta las fieras", me erija a mí, la Madre de Dios Hombre, que no menos sagradas las riberas le plugo hacer del mexicano lago que las del Hebro ya, que las del Tago

De acuerdo con esta interpretación, el arcoíris que adorna el Tepeyac (Argos) luce sobre el $c u$ de Tonantzin que ya es el templo de Guadalupe. De ser así, el arco representa la alianza que Dios sella con la tierra de México o, si se quiere, el "signo de concordia eterna”, al decir de Sigüenza y Góngora, que une el cerro con el paraíso.

En definitiva, mientras las aves funestas vinculan el Tepeyac con aquellos mitos que desde la tradición humanística expresaban las fuerzas del mundo inferior ${ }^{46}$, las harpadas lenguas lo hacen con la primavera que sigue al invierno. Dicho de otra manera, la lechuza, el búho y el murciélago resumen una alegoría moral de la noche, entendida ésta como un espacio sacrílego, corrupto y desapacible. La noche del Tepeyac se une estructural e inequívocamente con el México prehispánico descrito en el canto primero del poema y, en particular, con los sacrificios humanos descritos en el segundo. En efecto, la babélica confusión, el "ruido monstro de algazara y lloro", el "labirinto sonoroso" que emiten los mexicas cuando van a sacrificar a sus víctimas (II, 37-39) corresponden con los negros graznidos, los gemidos cansados y los abrumadores lamentos de las míticas aves. Es más, el silencio y el caos del Tepeyac emanan del "adúltero culto a espurias aras" (II, 37h) que allí se ofrenda a una diosa usurpadora o, como dice el poema, a la mentida Teotenantzin ${ }^{47}$. Este des-

45 El paralelismo con la Primavera indiana es indudable: "María soy, de Dios omnipotente / humilde Madre, Virgen soberana, / antorcha cuya luz indeficiente/ norte es lucido de la especie humana; / ara fragante en templo reverente / México erija donde fue profana / morada de Plutón, cuyos horrores / tala mi planta en tempestad de flores" (1668, octava 47).

46 Cf. José Pascual Buxó, "El Sueño de sor Juana: alegoría y modelo del mundo", Sor Juana Inés de la Cruz. Lectura barroca de la poesía, Renacimiento, Madrid, 2006, p. 110.

47 Dice la Virgen a Juan Diego en la primera aparición: “...Yo soy la que ambos orbes admirable / Madre aclaman, por serlo de Dios Hijo, / a quien 
concierto y esta confusión apretadamente referidos durante dos octavas, al oponerse "a la idea pitagórica del cosmos como resultado del orden y la armonía" 48 , articulan la primera serie del sistema guadalupano de concordancias: Tepeyac $\rightarrow$ invierno $\rightarrow$ esterilidad-silencio $\rightarrow$ gentilidad $\rightarrow$ noche $\rightarrow$ pecado.

A la alegoría moral de la noche, el poema opone naturalmente la alegoría moral del día, entendido como divina Aurora que restablece el orden cósmico. Donde antes se adoraba a una 'mentida deidad', donde imperaba un coro desafinado, ahora los pájaros-ángeles celebran la llegada de la Virgen, "que cual arco verdaderamente triunfal, se empeña en impulsarnos hacia todos los incrementos de paz y de felicidad plena" 49 . La universal batalla entre el día y la noche se reduce, en definitiva, a una simbología religiosa perfectamente establecida y la luz que trae la Guadalupana, como anticipaba el canto primero del poema, no puede desligarse de la luz que tiene la Inmaculada Concepción: las dos figuras vencen la noche del pecado, una a la serpientediablo, otra a Teotenatzin. El concertado coro de las aves articula, por tanto, la segunda serie de concordancias: Tepeyac $\rightarrow$ primavera $\rightarrow$ canto-flores $\rightarrow$ cristianismo $\rightarrow$ día $\rightarrow$ redención. Y, lo que a fin de cuentas importa señalar, todo el sistema se ordena en torno a la inflexión mitológica que rige la poética de Góngora: aves funestas, lira de Anfión, mito de las piérides, Orfeo. Por lo demás, ambos pasajes, el sombrío y el resplandeciente, hallan su punto de partida en diferentes versos gongorinos que poco o nada tienen que ver con la dimensión alegórico-moral que allí adquieren. Como diría Pascual Buxó respecto de las poéticas de la imitatio, las octavas de Castro establecen la deseada distancia entre el texto imitado y el imitante, la "consecuente transformación en los niveles semánticos más profundos” del modelo evocado en el nuevo poema ${ }^{50}$.

Por último. Al anotar las octavas examinadas de las aves protervas, Méndez Plancarte señaló su semejanza con el respectivo pasaje de las aves nocturnas del Primero sueño, con seguridad posterior al poema de Castro. La dependencia resulta innegable, pero no se limita sólo al plano formal, esto es, a que ambos

de hoy más será más agradable/ este monte -que entonces le desdijo / cuando su Teotenantzin se mentía / otra yo en él-, por ya posesión mía" (III, 31).

48 J. Pascual Buxó, art. cit., p. 116.

49 F. Picinelli, El mundo simbólico..., p. 196.

50 J. Pascual Buxó, "Sor Juana y Góngora: teoría y práctica de la imitación poética”, Sor Juana Inés de la Cruz. Lectura barroca de la poesía..., p. 347. 
poemas amplifican el pareado gongorino y presentan idénticos pájaros con similares alusiones: la construcción alegórica de la noche del Tepeyac se proyecta funcionalmente en la construcción alegórica del Primero sueño ${ }^{51}$. Esta relación invita a repensar las poéticas de la imitatio en el ámbito novohispano, sobre todo la mediación que pudo existir en la asimilación y evocación de la estética gongorina, cuánto del arte de Góngora no proviene directamente de él, sino de modelos menores, en este caso, de Francisco de Castro ${ }^{52}$.

Tadeo Pablo Stein

Universidad Autónoma Metropolitana - Cuajimalpa Universidad Autónoma de la Ciudad de México - Cuautepec

51 Observa el mismo Pascual Buxó: "En efecto, es en ese complejo paradigma de lo sacrílego o impío donde, al parecer, debe buscarse el significado 'moral' de las 'figuras' evocadas o descritas por sor Juana en las primeras secciones de 'La noche'; figuras cuyo difundido simbolismo le permitiría ir fijando el carácter confuso, irracional y perverso del mundo sublunar y, sucesivamente, el sosiego de los elementos naturales y el sueño profundo que, liberando el entendimiento humano de sus ataduras corporales, le dispondrían a la soñada aventura del "conocimiento posible" ("El Sueño de sor Juana: alegoría y modelo del mundo”, p. 111).

52 Retomo aquí la pregunta que se hace Martha Lilia Tenorio luego de demostrar las indiscutibles relaciones entre el gongorismo de Salazar y Torres y el de sor Juana o, como concluye la autora, "la productiva admiración de la monja por el poeta español" ("Agustín de Salazar y Torres: discípulo de Góngora, maestro de sor Juana”, NRFH, 58, 2010, p. 189). 